\title{
Mentors and Trainees Professional Interaction Features at the Modern Enterprises in Russia
}

\author{
Alfiya R. Masalimova ${ }^{1} \&$ Lidiya L. Sabirova ${ }^{1}$ \\ ${ }^{1}$ Kazan (Volga region) Federal University, Kazan, Russia \\ Correspondence: Alfiya R. Masalimova, The Institute of Psychology and Education, Kazan Federal University, \\ Kremlyovskaya Street 18, Kazan, 420008, Russia. E-mail: alfkazan@mail.ru
}

Received: December 29, 2014

Accepted: January 22, 2015 Online Published: February 11, 2015

doi:10.5539/res.v7n4p20

URL: http://dx.doi.org/10.5539/res.v7n4p20

\begin{abstract}
The modern condition of mentoring, which revived its traditions in conditions of information technology and intellectualization of modern enterprises is presented in the article. The meaning of such notions as a coach, mentor, intern, mentoring activities, corporate training, mentors and trainees professional cooperation peculiarities is revealed, selected types of mentoring on the content of activities and time characteristics are outlined and mentoring benefits are identified. The scope of the article's results application covers the practice of mentors corporate training, practice of mentors and trainees interaction, as well as the results obtained can be used in the development of modern provisions on mentoring.
\end{abstract}

Keywords: mentor, trainee, mentoring activities, mentoring, professional intercommunication

\section{Introduction}

Existing modern ideas, concepts, approaches, which are focused on vocational education system modernization, do not provide specialists full training for high-tech manufacture, which is characterized by computerization, intellectualization and emerging techniques and technologies (Shichkov 2013; Shaidullina, 2012). As a result, more than the half of professional knowledge volume the graduates of professional educational institutions are forced to get at job. Therefore, enterprises, receiving such graduates, have to search for optimal forms of their professional teaching (Masalimova et al., 2014; Merzon et al., 2015; Sibgatova et al., 2015; Shaidullina et al., 2015).

One of the forms aimed at young personnel professional competences effective formation and their corporate culture developing, facilitating successful social and professional adaptation is corporate training by certified mentoring corps, which allows to accumulate and share their professional experience, knowledge with the young personnel as well as encourages the disclosure of young specialists personal potential with the purpose of their professional development's individual trajectories definition.

In the sphere of activities, mentoring refers to the services provision, which includes information and professional experience transferring, the young personnel's personality potential disclosure. On functional-purpose application mentoring performs the following functions: organizational-managing, social-pedagogical, information and consultation, the correction-reorganization functions. By the content it is a kind of informal education, in which young employees digest the information, acquire professional knowledge and experience. On procedural characteristics mentoring involves the obtained, acquired and processed information transformation in formed professional competence (Klucharev \& Pakhomova, 2008).

In the course of research we have seen that the field of mentoring system application are still expanded, and currently, this system is applied in the following spheres:

1) Areas in which technological progress is far ahead the process of professional knowledge and skills updating (IT, manufacture, i.e. sectors where the qualifications of the personnel doesn't demand the needs of the company and adversely affect the results of operations of the entire organization and leads to considerable financial losses.

2) Areas in which practical experience and high skills play a crucial role in professional duties implementation. 
3) Professional activity, which is characterized by a high risk degree.

4) The enterprises where routinely technological procedures and equipment are periodically updated (industrial companies).

5) Enterprises, which are characterized by the employee turnover and, consequently, there is a need for mass and operational training of qualified personnel (Andreeva \& Nechaev, 2013).

However, for mentoring system effective organization modern companies should be aware of its following characteristics:

- In conditions of modern enterprises the mentoring should be directed not only to professional knowledge and experience transferring, but also on personal potential development of the employee and to assume a more general training, basic skills;

- Mentoring has long implementation period that require organization and system approach. The fact that the necessary knowledge and skills are not transmitted at once or from time to time, so mentoring is productive when it is specially organized and under controll;

- Mentoring requires investment (mentors financial incentives, methodological training materials, additional supplies with possible defects in the work performance by a young worker etc);

- The process of new employees training requires mentor additional efforts, in addition to the main duties, what is to be considered when planning his activities, his work motivation system development and at the recourses cost taking into account (Magura \& Kurbatova, 2003; Mrathuzina et al, 2015).

The previous researches, which were made by Batyshev (1985), Vershlovsky et al. (1987), Makhmutov (1981) are devoted to mentoring forming historical aspects study. Mentoring activities psychological-pedagogical bases are revealed in scientific works, made by Batyshev (1985), Osipov and Neprimerova (1978). Mentoring system's organization peculiarities in the sphere of industrial manufacture are revealed in research of Plotnikov (2006), Charina (2004) and Masalimova (2013).

However, there are only few scientific works, which are devoted to the problem of modern mentoring and they have only discussion character.

\section{Methodological Framework}

The goal of modern mentoring is aimed at young workers corporate forming and professional competences development to overcome information and valuable barriers in their professional activities and their social and professional adaptation, as well as their potential revealing with the purpose of their individual professional development trajectories defining.

The objectives of modern mentoring are: young workers training and education; increasing of productivity at manufacture, new and experienced employees quality improving in accordance with the standards and regulations, which were adopted at the enterprise, young workers corporate culture forming, participation in corporate standards implementation and their continuity ensuring, young workers career opportunities providing, reduction of staff turnover, a cohesive team of the company forming, the company image forming.

The analysis of normative documents on mentoring at the enterprises of Russia, JSC Tatneft, JSC "Severstal", JSC "LUKOIL", Kazan state gunpowder plant has allowed to reveal the essence of the following concepts related to the research problem:

Mentoring is one of the training forms at the workplace, aimed at young worker's applied professional and cultural competences development.

Mentoring activities - activities aimed at the formation of corporate and development of applied professional competences of young workers to overcome information and valuable barriers in professional activities and their social and professional adaptation, as well as the young specialists potential disclosure with the purpose of individual professional trajectories defining in their development.

Mentor is an experienced worker who is responsible for planning and organization of his trainee's effective professional development program and promote his trainee's social and professional adaptation at the enterprise.

Intern - young worker or specialist, adopted on permanent work and carrying out his professional work under the guidance of the mentor for one year. 
Corporate training is the process of employees knowledge, skills and competencies improving at the enterprise on the educational programs developed in cooperation with professional education institutions, research institutes and enterprises in a unite orientation and taking into account the interests of both the students and the whole enterprise to ensure its innovativeness and competitiveness (Masalimova \& Sabirova, 2014).

During the research the following methods were used: the analysis of philosophical, psychological-pedagogical and scientific-methodical literature on the problem of the research, analysis of normative documents and products of activities, monitoring; survey of teachers and students; a survey of employers; systematization and generalization of facts and concepts, modeling, design, method of expert estimates, the study and generalization of the mentoring experience at enterprises of Russia.

\section{Results}

Any modern enterprise should implement and develop mentoring, because this form is not confined to one profile but aimed at achieving different relevant objectives of the enterprise (Zevunov, 2009). The following advantages of mentoring activity can be pointed out: the improving of the quality of young workers training at various levels taking into account the real needs and interests of enterprises; reducing of new techniques and technologies mastery time; the creation of a united educational and manufacturing field of the enterprise; reducing of the financial costs on training and staff development; the acceleration of socio-professional adaptation of new employees to the working conditions at the plant and the mastery of their occupation duties and corporate standards.

However, some problems connected with mentors' corporate training to implement their activities can be pointed out in modern mentoring practice: insufficient training of mentoring staff to innovative housing reforms in the content and methods of training; rapid obsolescence of scientific and teaching materials, including textbooks; mentors being interested in manufacturing tasks solving.

In order to understand the problems arising in corporate education system, it seems necessary to assess the existing models in practices of corporate education, which correspond with specific requirements of the organization of educational process in enterprises:

Problem-oriented model of corporate training based on psychological and methodical approach allows taking into account a wide range of tasks of personnel corporate training, using the "problem situation" method, which perfectly fits into the everyday life of the enterprise (Helfman et al., 2009).

Complementary and displacing models, based on correctional formative approach, which allows to change the vector of employees professional behavior, to adapt it to varying external conditions, to form the missing professional competences (Pevzner et al., 2002).

Model of corporate training, which puts a focus on in-service training (Bazarova \& Eremina, 2002).

Innovative model, which orients corporate training process towards an innovative way, relying on the bank of standard solutions for typical problems (Kartashova, 2009).

Personality-oriented model focuses on various aspects that help the employee to develop his creative approach towards his professional duties performance (Kibanov \& Durakova, 2005).

Information and advisory model suggests innovative character by integrating two interrelated processes: training (informing), the result of which is an increase of knowledge and competence of employees, and consultancy, the result of which is personal problems solving of professional staff (Zevunov, 2009).

Metacognitive model is aimed to form a "learning organization" that can act as a subject of corporate training and to hold an open and reflective cognitive position towards external and internal organizational environment (Karpov \& Skityaeva, 2008).

Multiplication model is in great request among enterprises with limited financial resources and which are forced to have their teachers-multiplicators (Morita, 1990).

Model of corporate competition is aimed at creating a competitive advantage among company's staff in order to provide competition within the organization (Isaev et al., 2013).

Leadership model is aimed at purpose-oriented shaping of leadership qualities among managerial staff, and includes an assessment of leadership style of the training process participants, team development, intergroup development, drawing up an organizational model based on leadership principle and its implementation as well (Vandenbusscke et al., 2006). 
The analysis of existing models of corporate training, aimed at solving problems of training of both workers and specialists of modern companies, revealed their flaws, expressed primarily in their focus on narrow professional corporate training; lack of involvement in the process of mentoring body of young workers corporate training; lack of mechanisms of interaction between mentors of different qualifications and levels and young workers.

During the research we found that young workers need professional advice of specialists of different profiles and turn to other mentors who serve as consultants. In this regard, peculiarities of professional interaction between trainees and mentors are the manifestation of vocational complementary nature of the interaction between mentors of different qualifications and levels with young employees, who are interested not only in their professional duties, but also in other spheres (for example, a young specialist - engineer is interested in the economic side of the project. In this case he refers to the mentor-economist). Symbiosis in the team, consisting of complementary mentors of different profiles and levels with the developed competencies for his activity implementation serves as the technological finding, optimizing the overall structure of specialists corporate training at the enterprise, allowing any employee to extrapolate the acquired professional experience.

Such interaction between mentors and trainees promotes deeper mutual problems reflection and leads to a constructive dialogue to solve them, which very effectively impact not only on the professional growth of trainees, but also mentors.

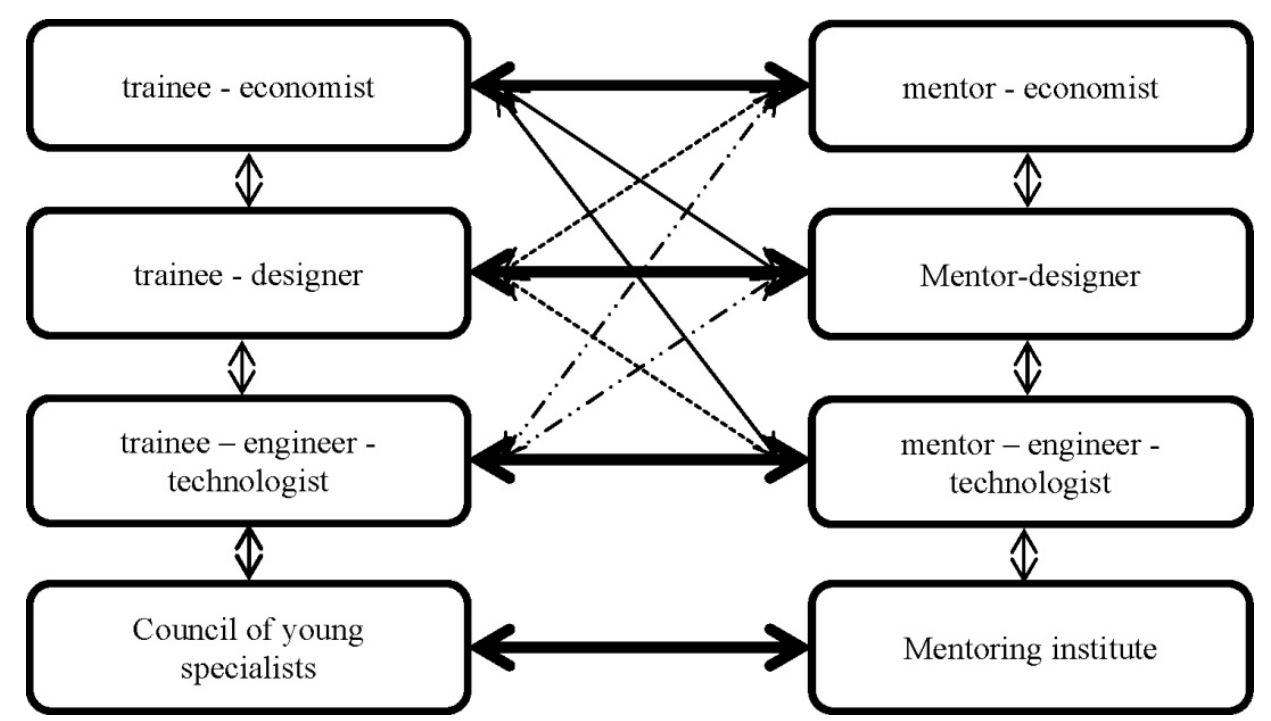

Figure 1. Professional interaction of trainees and mentors

This interaction becomes relevant in connection with ongoing updates at the enterprise requiring professional and social mobility its employees, their abilities to work in team for collective decision making and to develop the correct strategy for orientation in non-standard situations.

Mutually beneficial cooperation of young employees and mentors is the Central idea of this cooperation, ensuring the supremacy of the joint actions of the project team, which in its single and independent implementation cannot provide an adequate level of decision of organizational and methodical problems of young professionals corporate training. The superiority of the project team is that the more diverse the team which consists of mentors of different profiles and levels (engineers, technicians, designers, engineers, economists and so on), the larger the result of its work, since it increases the technical, technological and economic levels of young professionals corporate training's problems decision by combining diverse expertise, increasing the amount of the competitiveness of the team project. Such complementary professional collaboration of young professionals and mentors contributes to the enterprises collective knowledge formation.

On the content of activities, there are three most extensive types of mentoring in sociological studies: corporate, professional and social mentoring. Corporate mentoring involves corporate values transferring, acquaintance with traditions and history of the company, with the best leaders of manufacture. Social 
mentoring is aimed at young specialists' social and psychological problems solving. The role of social mentor can be executed by any individual possessing the ability and willingness to help others.

Professional mentoring is focused on young specialists professional support in the corporate training process aimed at professional qualifications getting (Rudavina \& Ecomasov, 2011).

However, according the presented mechanism of system and complementary interaction of corporate training young specialists, this typology is supplemented with complementary mentoring, representing a complementary professional interaction of young workers and mentors, contributing to the collective knowledge forming.

By the time characteristics the following types of mentoring are outlined: episodic, implying a temporary, partial implementation of mentoring in connection with new techniques and technologies implementation in enterprise practice; periodic one, involving discrete nature of mentoring implementation in connection with the periodic introduction of employees in a new status; systematic mentoring with constant and continuous update of intellectual base personnel at the enterprises in connection with informational component increasing.

Mentoring as a mechanism of young specialists social and professional adaptation in the enterprise is carried out in vocational training, situational advice in professional activity process, knowledge and experience transferring to employees-beginners, their personal potential disclosure, manufacture process algorithms demonstration and the results joint analysis.

\section{Conclusion}

Professional interaction between trainees and mentors, involving professional complementary cooperation of different qualifications and levels mentors with the young staff, is directed on its participants' professional and social mobility forming, skills developing to work in team for collective decision making and its behavior's right strategy constructing.

Such mentors and trainees interaction promotes mutual problems deeper reflection and leads to a constructive dialogue to solve them, that is very effectively impact not only on the professional growth of trainees, but also mentors.

Professional interaction of trainees and mentors contributes to:

- In organizational aspect to: teaching process corporate management implementation; enterprise's all participants' interaction in the process of students' corporate training (administration centers providing training; managers; trainers and trainees);

- In pedagogical aspect: corporate training's traditional model transformation into innovative one, which is based on reflective-dialogical interaction of this process participants; giving opportunities for young personnel professional growth and career development; internal communications system formation, which ensure enterprise cultural norms and traditions translation;

- In personal aspect: professional competences formation of young professionals and mentors; giving opportunities for professional growth, self-realization and career path development; staff corporate culture formation, enterprise's positive image creation;

- In economic aspect: possibility of a young specialist getting, who can meet modern requirements of the enterprise, and as a result - time and financial expenses reducing for his subsequent corporate training; own personnel training costs optimization; labor resources deficit compensation through in-service training at the enterprise.

\section{Acknowledgments}

The work is performed according to the Russian Government Program of Competitive Growth of Kazan Federal University

\section{References}

Andreeva, E. S., \& Nechaev, A. S. (2013). The Mechanism of an Innovative Development of the Industrial Enterprise. World Applied Sciences Journal, 27, 21-23.

Batyshev, A. S. (1985). Pedagogical system of mentoring in the workplace. Moscow: Higher School.

Batyshev, S. Y. (1985). Production pedagogy (p. 672). Mechanical Engineering Press.

Bazarova, T. Y., \& Eremina, B. L. (2002). Personnel management: A textbook for high schools (p. 560). UNITY 
Press.

Charina, E. V. (2004). Relationships in the mentor-Young professional in the process of professionalization (p. 160) (M.S. thesis, Far Eastern State University of Railways).

Helfman, E. G., Holodnaya, M. I., Bashirova, I. A., \& Blinov, T. L. (2009). Modern problems of education: Theory and practice (p. 298). Ural State Pedagogical University Press.

Isaev, A. V., Isaeva L. A., \& Kravets, A. G. (2013). Individualized Educational Trajectory: Educational Courses Integration Submitted. World Applied Sciences Journal, 24, 62-67.

Karpov, A. V., \& Skityaeva, I. M. (2008). In-house training as a resource for organizational development. Professional Education Journal. Retrieved April 25, 2008, from http:/www.hrm.ru/vnutrifirmennoe-obuchenie-kak-resurs-organizacionnogo-razvitija

Kartashova, L. V. (2009). Human Resource Management (p. 107). INFRA Press.

Kibanov, A. Y., \& Durakova, I. B. (2005). Management staff of the organization (p. 414). Exam Press.

Klucharev, G. A., \& Pakhomova, H. I. (2008). Corporate education: Alternative government programs in additional education. Journal of Continuing education in the political and economic contexts, 3(2), 134-160.

Magura, M. I., \& Kurbatova, M. B. (2003). Organization of training. Moscow: MG.

Makhmutov, M. I. (1981). Pedagogy mentoring (p. 123). Modern Russia Press.

Masalimova, A. R. (2013). Corporate training the mentors (p. 183). Kazan: Printing Service-XXI Century Press.

Masalimova, A. R., \& Sabirova L. L. (2014). Multi-dimentional classification of types and forms of corporate education. American Journal of Applied Sciences, 11(7), 1054-1058. http://dx.doi.org/10.3844/ajassp.2014.1054.1058

Masalimova, A. R., Zakirova, V. G., Chernova, Y. A., Drovnikov, A. S., Shaidullina, A. R., \& Sakhieva, R. G. (2014). Structure and content of mentors psychological and pedagogical training curriculum. Life Sci J., $11(7 \mathrm{~s}), 381-386$.

Merzon, E. E., Fayzullina, A. R., Ibatullin, R .R., Krylov, D. A., Schepkina, N. K., \& Pavlushkina, T. V. (2015). Organizational and pedagogical conditions of academic mobility development of students at school of higher professional education. Review of European Studies, 7(1), 46-51.

Morita, A. (1990). Made in Japan (p. 206). Progress Press.

Mrathuzina, G. F., Fayzullina, A. R., \& Saglam, F. A. (2015). Substantive, Methodological and Organizational Discourse in Oriental History Learning at School and University. Review of European Studies, 7(1), 57-62

Osipov, P. N., \& Neprimerova, G. A. (1978). Approximate program psychological and pedagogical training mentors in national universities (p. 32). Kazan: Kazan State University Press.

Pevzner, M. N., Zaychenko, O. M., Buketov, V. O., Gorycheva, S. N., Petrov, A. V., \& Shirin, A. G (2002). Scientific and methodological support for school personnel: Pedagogical counseling and supervision (p. 316). Novgorod State University Press.

Plotnikov, A. N. (2006). Formation of professional and pedagogical competence master-mentor in terms of course preparation (p. 185) (M.S. thesis, Volgograd State Pedagogical University).

Rudavina, E. R., \& Ekomasov, V. V. (2011). Big Book of HR Director (p. 368). St. Petersburg: Peter.

Shaidullina, A. R. (2012). Regional Experience of Integration in System Vocational School-High School-Manufacture. Memoirs of Almetyevsk State Oil Institute, 2, 306-312.

Shaidullina A. R., Krylov, D. A., Sadovaya, V. V., Yunusova, G. R., Glebov, S. O., Masalimova, A. R., \& Korshunova, I. V. (2015). Model of Vocational School, High School and Manufacture Integration in the Regional System of Professional Education. Review of European Studies, 7(1), 63-67.

Shichkov, A. N. (2013). The Content of the High Engineering Education. World Applied Sciences Journal, 27, 343-348.

Sibgatova, K. I., Mirzagalyamova, Z. N., Pupysheva, E. L., Mirzanagimova, F. I., Shkinderova, I. N., Nuriyeva, E. N., ... Schepkina, N. K. (2015). The Educational Institution Teachers and Professional Community 
Representatives' Readiness Formation for the Joint Pupils' Career Guidance Implementation. Review of European Studies, 7(1), 74-79.

Vandenbusscke, J., Aghion, A., \& Meghir, C. (2006). Growth Distance to Frontier and Composition of Human Capital. Journal of Economic Growth, 11(2), 97-127.

Vershlovsky, S. G., Wisburg, A. A., \& Hodakov, A. I. (1987). Organize training mentors in the workplace (p. 176). Moscow Profizdat Press. http://dx.doi.org/10.1007/s10887-006-9002-y

Zevunov, A. V. (2009). Corporate training small businesses (M. S. thesis, Russia, MI: Nizhny Novgorod State University by N.I.Lobachevsky name).

\section{Copyrights}

Copyright for this article is retained by the author(s), with first publication rights granted to the journal. This is an open-access article distributed under the terms and conditions of the Creative Commons Attribution license (http://creativecommons.org/licenses/by/3.0/). 